\title{
Precipitation isotope characteristics and climatic controls at a continental and an island site in Northeast Asia
}

\author{
Jianrong Liu ${ }^{1,2}$, Xianfang Song ${ }^{1, *}$, Guobin Fu ${ }^{3}$, Xin Liu ${ }^{1,2}$, Yinghua Zhang ${ }^{1}$, \\ Dongmei Han ${ }^{1}$
}

\author{
${ }^{1}$ Key Laboratory of Water Cycle \& Related Land Surface Processes, Institute of Geographic Sciences and \\ Natural Resources Research, Chinese Academy of Sciences, 11A Datun Road, Chaoyang District, Beijing, 100101, PR China \\ ${ }^{2}$ Graduate University of Chinese Academy of Sciences, 19A Yu Quan Road, Beijing, 100049, PR China \\ ${ }^{3}$ CSIRO Land and Water, Private Bag 5, Wembley, Western Australia 6913, Australia
}

\begin{abstract}
In mid-latitude continental and island regions, the isotope composition of air masses often varies according to both their origin and their interaction with topography along their path of travel. Comparison of stable isotopes in continental and island precipitation events can reveal climatic controls upon isotopic content and yield information about patterns of atmospheric circulation. The overall deuterium (D) and oxygen-18 $\left({ }^{18} \mathrm{O}\right)$ characteristics of 64 precipitation events observed in continental Beijing, China, and 109 precipitation events observed at Seongsan (Jeju Island, Republic of Korea) were investigated. The established local meteoric water lines, $\delta \mathrm{D}=7.49 \delta^{18} \mathrm{O}+1.53\left(\mathrm{R}^{2}=0.96, \mathrm{n}=64\right)$ and $\delta \mathrm{D}=8.36 \delta^{18} \mathrm{O}+19.05\left(\mathrm{R}^{2}=0.86, \mathrm{n}=109\right)$, indicated periodic drought in Beijing and a kinetic effect in the condensation process in Seongsan. To trace moisture origins and transport paths for all precipitation events, the $96 \mathrm{~h}$ backward trajectories of air masses arriving at $3000 \mathrm{~m}$ above ground level were calculated and categorized using the Hybrid Single Particle Lagrangian Integrated Trajectory (HYSPLIT) model. The results indicate that during the Asian monsoon period, the air mass categories represented at Seongsan were principally from the southeast, southwest, and continental vicinity $(\mathrm{CV})$. Those observed for Beijing were more varied (northwest, west, north, marine vicinity, south, and CV). Additionally, the meteorological controlling factors of each air mass category were identified using non-linear stepwise regression. The precipitation amount was the main predictor for ${ }^{18} \mathrm{O}$ in precipitation in Seongsan, while the controlling factors involved in Beijing were more complicated.
\end{abstract}

KEY WORDS: $\delta^{18} \mathrm{O} \cdot \delta \mathrm{D} \cdot$ Event precipitation $\cdot$ Meteorological conditions $\cdot$ Backward trajectory HYSPLIT Resale or republication not permitted without written consent of the publisher

\section{INTRODUCTION}

The systematic analysis of isotopes in precipitation provides basic data for the use of isotope-specific tools in hydrological and meteorological investigations. The Global Network of Isotopes in Precipitation (GNIP) observation project, initiated by the International Atomic Energy Agency (IAEA) and the World Meteorological Organization (WMO), is the largest endeavor of its type (Rozanski et al. 1993). The climatological isotope patterns obtained from these measurements, recorded on an almost monthly basis, have typically been interpreted in terms of different isotope effects (Dansgaard 1964). Instead of being related to isolated physical processes, these effects have generally been found to reflect a complex sequence of fractionation during the phase transitions of water from evaporation to precipitation 
(Pfahl \& Wernli 2008). However, variations in the stable isotopes of event-based precipitation generally offer more information concerning potential synoptic controls upon isotopic content, and thus yield information about the circulation and structure of the atmosphere (Barras \& Simmonds 2008). These data are particularly significant for the study of mid-latitude regions, where water cycle processes are more complex (Gedzelman \& Lawrence 1982, Lawrence et al. 1982). Furthermore, better explanations of fluctuations in isotope ratios could result from an analysis that includes both the isotopic variations associated with changes in water vapor origins and the meteorological conditions attendant to particular transport paths (e.g. temperature, precipitation amount, and processes involving evaporation of rain drops falling into the dry atmosphere beneath the cloud base).

The Hybrid Single Particle Lagrangian Integrated Trajectory (HYSPLIT) model developed by the National Oceanic and Atmospheric Administration (NOAA) Air Resources Laboratory (Draxler \& Rolph 2003, Rolph 2010) is designed for regional scale trajectory analysis, such as that pertaining to the regional transport of aerosols (e.g. Lee et al. 2004) and water vapor. Strong et al. (2007) analyzed the moisture transport paths in the southwestern USA by using a high temporal resolution of deuterium (D) records and the HYSPLIT model. Trajectory analyses provided consistent evidence that the large temporal and vertical variations in D concentrations were due primarily to advection of water from different source regions. Pfahl \& Wernli (2008) correlated data concerning stable isotope composition in eastern Mediterranean precipitation with the pertinent $10 \mathrm{~d}$ backward trajectories to establish the meteorological conditions in the evaporation regions. Barras \& Simmonds (2008) investigated an event-based record of oxygen-18 $\left({ }^{18} \mathrm{O}\right)$ in precipitation at Margate in Tasmania, Australia, by using 3D Lagrangian trajectories and composites of ERA40 $850 \mathrm{hPa}$ geopotential height for the years 1994-2002. They found that moisture entrainment occurred during the $48 \mathrm{~h}$ period prior to arrival for all precipitating air masses.

The comparison of stable isotope characteristics contained in precipitation events at continental (Beijing, China) and island (Seongsan, Republic of Korea) sites is interesting, as both of these 2 sites have mid-latitude environments, and their air masses interact with complicated topography throughout their path from source region to site of precipitation. Such a comparison provides information about climatic controls under the influence of the Asian monsoon. The present study thus identified moisture origins and transport paths for precipitation events by using the HYSPLIT model. Dominant meteorological controls for different air mass categories were also investigated, using the stepwise regression method.

\section{OBSERVATION SITES}

Both of the 2 observation sites have mid-latitude climates (Fig. 1) under the influences of the West Wind Belt and the Asian monsoon. Because of the control of the Mongolian High in winter, the intrusion of continental high-latitude air masses brought by northerly winds leads to a cold and dry climate, whereas sufficient moisture from the southern Pacific Ocean and the Indian Ocean, transported by the Asian monsoon, arrives due to the subtropical High in summer, resulting in warm and humid climatic conditions (Huang et al. 2003, Wei et al. 2008.

Beijing, China, located on the northern edge of the North China Plain and surrounded by mountains on its western, northern, and eastern sides, has a typical half-moist continental monsoon climate (Guo et al. 2006). The average annual temperature is $12.1^{\circ} \mathrm{C}$, with an average annual precipitation of $591 \mathrm{~mm}$; $72.8 \%$ of annual precipitation based on 1951-2008 averages occurs in the summer months (JuneAugust). Winter precipitation is scarce and accounts for merely $1.8 \%$ of the annual amount. During the observation period, the average temperatures were $1.3^{\circ} \mathrm{C}$ higher than long-term averages in 2006 and

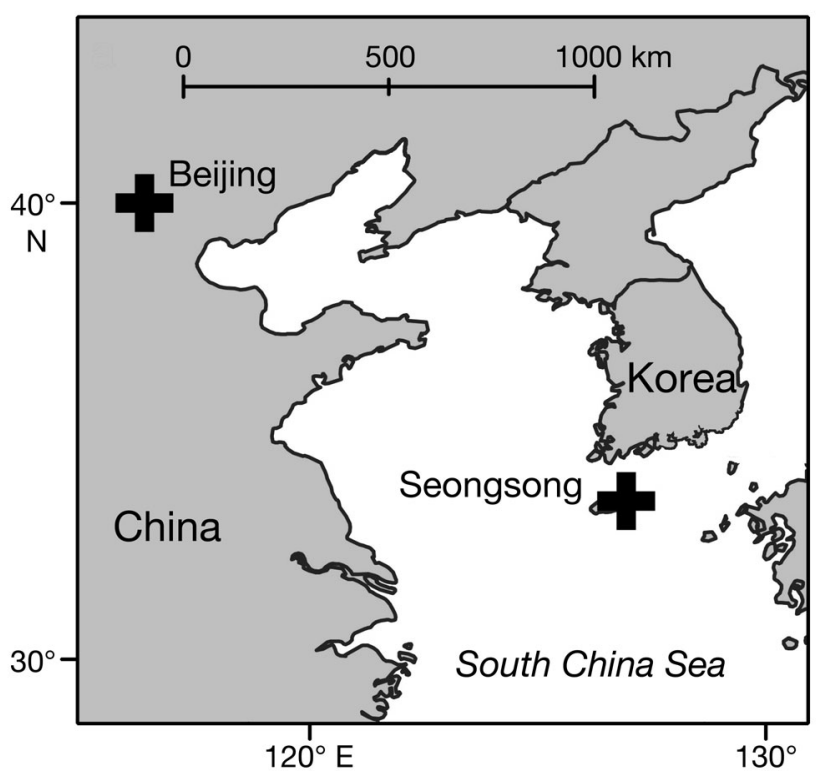

Fig. 1. Locations of the 2 observation sites 

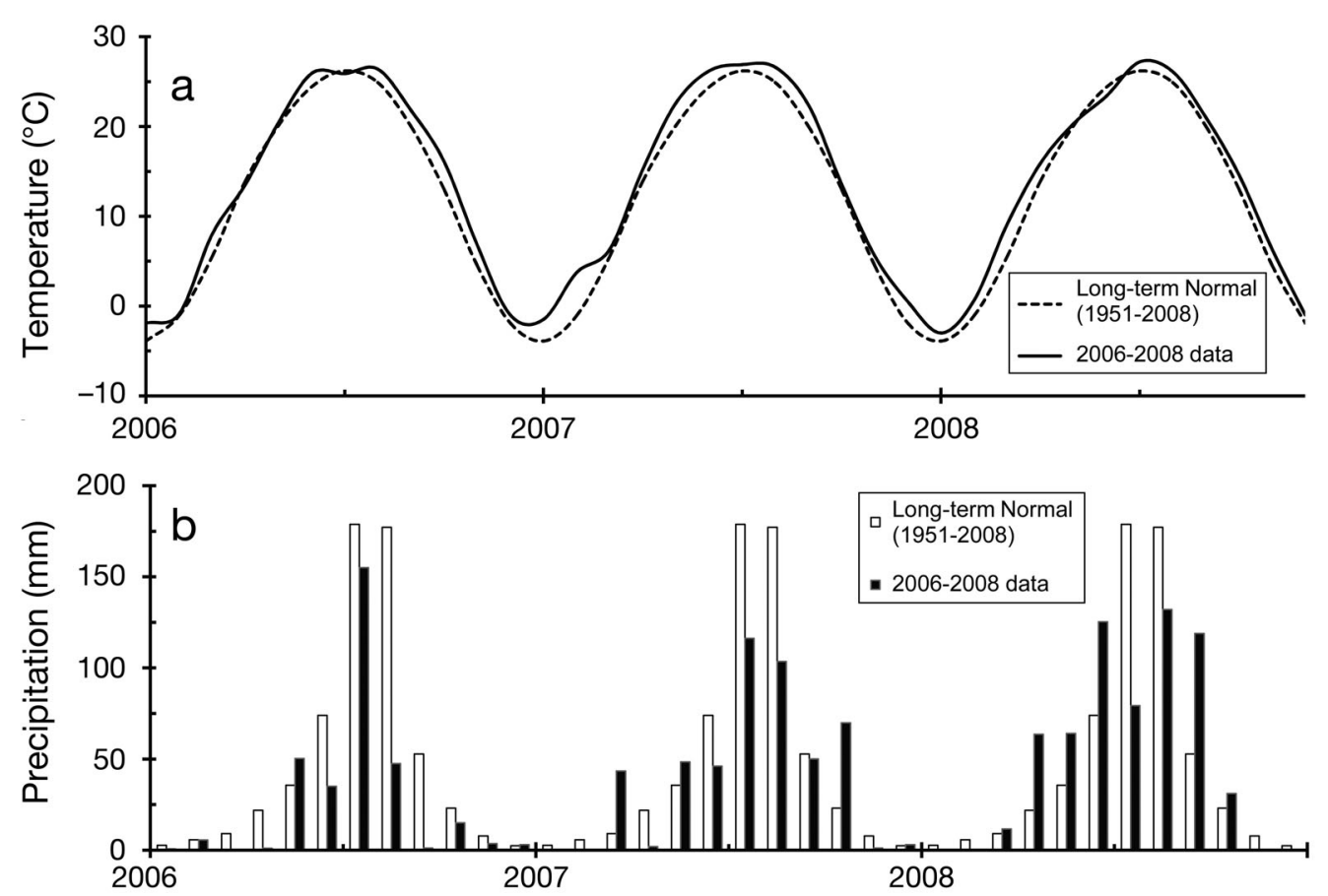

Fig. 2. (a) Monthly average temperatures, and (b) total monthly precipitation amount for the observation period 2006-2008, compared to the long-term average (1951-2008) at Beijing

2008, and $1.9^{\circ} \mathrm{C}$ higher than in 2007 (Fig. 2a). Precipitation levels were $46.2 \%$ and $18.1 \%$ below normal for 2006 and 2007 and $6 \%$ above normal for 2008 (Fig. 2b).

Seongsan (Jeju Island, Republic of Korea) is located about $100 \mathrm{~km}$ SW of the Korean Peninsula, between $33^{\circ} 12^{\prime}$ and $33^{\circ} 34^{\prime} \mathrm{N}$, and is bordered by the Yellow Sea on the west, the Korean Strait on the northeast, and the East China Sea on the south. It experiences large swings in mean monthly temperature $\left(>20^{\circ} \mathrm{C}\right)$ and precipitation $\left(>150 \mathrm{~mm}_{\text {; Kwon }}\right.$ 1985). The monthly temperature averages were near the $70 \mathrm{yr}$ average during the observation period. The precipitation in the first summer of the observation period was $61 \%$ heavier than normal and $12 \%$ lower than normal in the second summer. Precipitation in the first winter was $32 \%$ below normal and near normal in the second winter (Lee et al. 2003).

\section{DATA AND METHODS}

\subsection{Stable isotope data}

We used 2 datasets of $\mathrm{D}$ and ${ }^{18} \mathrm{O}$ :

(1) Precipitation samples collected at the Institute of Geographic Sciences and Natural Resources Research (IGSNRR) of the Chinese Academy of Sci- ences (CAS), Beijing, China. From 12 January 2006 to 10 September 2008, 64 precipitation events were sampled using a collector on the roof of the IGSNRR's main building $\left(116.3853^{\circ} \mathrm{E}, 40.0031^{\circ} \mathrm{N}\right.$, $45 \mathrm{~m}$ asl, $\sim 10 \mathrm{~m}$ above ground level, agl). The rainfall collector consisted of a polyethylene bottle with a funnel. A ping pong ball covered in the mouth of the funnel to prevent evaporation. Snow samples were collected using a pail installed on the roof. After each snowfall event, snow samples were melted at room temperature (Liu et al. 2010a). The start and end times of each event were calculated automatically by a nearby rain gauge. Most of the precipitation events during the observation period lasted for a few hours, and those spanning multiple days were not considered in the present study. Samples were transferred into $50 \mathrm{ml}$ polyethylene bottles and analyzed with respect to $\mathrm{D}$ and ${ }^{18} \mathrm{O}$ using the Finnigan MAT253 mass spectrometer and the Temperature Conversion Elemental Analyzer (TC/EA) method at the Environmental Isotope Laboratory of IGSNRR. Measurement accuracies were consistently $\pm 1 \%$ for $\mathrm{D}$ and $\pm 0.3 \%$ for ${ }^{18} \mathrm{O}$. Most of the samples were collected during the summer months (JuneAugust).

(2) Precipitation samples obtained from Seongsan (Jeju Island, Republic of Korea, $126.933^{\circ} \mathrm{E}, 33.4656^{\circ} \mathrm{N}$, $25 \mathrm{~m}$ asl), which is a GNIP station where event precipi- 
tation samples have been collected from 25 May 1995 to 2 May 1997 (data were taken from http://isohis. iaea.org).

$\mathrm{D}$ and ${ }^{18} \mathrm{O}$ are expressed as

$$
\delta(\%)=\left(R_{\text {sample }}-R_{\text {standard }}\right) / R_{\text {standard }} \times 1000
$$

where $R$ refers to the $\mathrm{D} / \mathrm{H}$ or ${ }^{18} \mathrm{O} /{ }^{16} \mathrm{O}$ ratio, and the standard refers to the Vienna Standard Mean Ocean Water. The weighted $\delta$ values $\left(\delta^{18} \mathrm{O}_{p}\right)$ were calculated by averages of event precipitation amount.

\subsection{Meteorological data}

Data concerning daily meteorological variables, including surface air temperature (minimum temperature, $T_{\text {mini }}$ maximum temperature, $T_{\text {maxi }}$ and mean temperature, $T)$, precipitation amount $(P)$, relative humidity $(R H)$, wind speed $(W S)$, sunshine duration $(S D)$, and vapor pressure $(V p)$, for the Beijing site were provided by the China Meteorological Data Sharing Service System. Similar meteorological variables for Seongsan were obtained through the NOAA Satellite and Information Service, including $T$, $P, W S, V p$, and dew point temperature $(D T)$.

\subsection{HYSPLIT model}

Backward trajectories were calculated by using the HYSPLIT model (Rolph 2010) for 96 h duration with $3000 \mathrm{~m}$ agl ending level to illustrate the moisture history of the air masses associated with each event. Meteorological input for the trajectory model was the REANALYSIS dataset (global, 1948-present), reprocessed from NOAA's NCEP Final Analysis data by the Air Resources Laboratory (Kalnay et al. 1996). The data pertained to the $2.5^{\circ} \times 2.5^{\circ}$ latitudelongitude global grid, $144 \times 73$ points from $90^{\circ} \mathrm{N}$ to $90^{\circ} \mathrm{S}, 0$ to $357.5^{\circ} \mathrm{E}$ and involved an output every $6 \mathrm{~h}$ (00:00, 06:00, 12:00, 18:00 UTC).

For each precipitation event, trajectories were calculated at 3 levels, $1500 \mathrm{~m}(\sim 850 \mathrm{hPa}), 3000 \mathrm{~m}$ $(\sim 750 \mathrm{hPa})$, and $5500 \mathrm{~m}(\sim 500 \mathrm{hPa})$, to determine the most representative origin height. The results showed that most of the trajectories were similar with respect to the origin and transport path at each of the 3 levels (figures not shown). As precipitation usually occurred at a height of no more than $3000 \mathrm{~m}$, the $3000 \mathrm{~m}$ level was selected here. Furthermore, air mass trajectories at multiple time intervals $(24,48,72,96$, and $120 \mathrm{~h})$ were also calculated for each event. The results indicate that all trajectories were similar in origin and transport direction, varying only with respect to the length of the paths involved.

\section{RESULTS AND DISCUSSION}

\subsection{Characteristics of $\delta^{18} \mathrm{O}$ in precipitation events}

\subsubsection{Temporal variations in $\delta^{18} \mathrm{O}$}

The continental Beijing site had wider ranges in $\delta \mathrm{D}$ and $\delta^{18} \mathrm{O}(-133.26$ to $4.02 \%$ and -17.51 to $0.25 \%$, respectively) than the Seongsan island site (-105 to $20 \%$ and -13.5 to $-1.0 \%$, respectively). Most of the depleted $\delta^{18} \mathrm{O}$ values were in phase with the heaviest precipitation events for Seongsan (e.g. 1 July 1995, with $\delta^{18} \mathrm{O}=-13.5 \%$ and $P=317.5 \mathrm{~mm}$; and 21 June 1996, with $\delta^{18} \mathrm{O}=-10.8 \%$ and $\left.P=166.5 \mathrm{~mm}\right)$ but were not in phase for Beijing (e.g. 6 February 2006, with the $\delta^{18} \mathrm{O}=-17.51 \%$ and $P=18 \mathrm{~mm}$; and 4 March 2007, with the $\delta^{18} \mathrm{O}=-16.93 \%$ and $P=26.6 \mathrm{~mm}$; Fig. 3a,b). At Seongsan, the most depleted $\delta^{18} \mathrm{O}_{p}$ appeared during the summer, which was a reflection of precipitation amount (Table 1). During this period, the prevailing Asian summer monsoon brings huge amounts of rainfall and the most depleted isotopic composition to island sites (Dansgaard 1964, Lawrence \& Gedzelman 1996). In contrast to the monthly samples collected in the rainy season, no amount effect was detected at the Beijing site (Liu et al. 2010a).

Table 1. Statistical results of the observed precipitation $\delta^{18} \mathrm{O}$ $($ mean $\pm \mathrm{SD}) . P R F_{1}$ : seasonal precipitation amount as a percentage of total precipitation amount; SD: standard deviation of $\delta^{18} \mathrm{O}$ for each season; $\delta / T$ : linear correlation coefficient between $\delta^{18} \mathrm{O}$ and temperature; $\delta / P$ : linear correlation coefficient between $\delta^{18} \mathrm{O}$ and precipitation amount. ${ }^{*} \mathrm{p}=0.05$ level, ${ }^{* *} \mathrm{p}=0.01$

\begin{tabular}{|lrrrlc|}
\hline \multicolumn{1}{|c}{ Events } & $\begin{array}{c}P R F_{1} \\
(\%)\end{array}$ & $\begin{array}{c}\delta^{18} \mathrm{O}_{p} \pm \mathrm{SD} \\
(\%)\end{array}$ & $\delta / T$ & $\delta / P$ \\
\hline Beijing & & & & & \\
Spring & 10 & 10.6 & $-7.4 \pm 5.6$ & $0.879^{* *}$ & -0.272 \\
Summer & 45 & 79.5 & $-7.2 \pm 2.4$ & 0.121 & -0.135 \\
Autumn & 6 & 7.8 & $-5.8 \pm 3.0$ & $0.886^{*}$ & -0.390 \\
Winter & 3 & 2.1 & $-13.0 \pm 7.0$ & 0.807 & -0.646 \\
& & & & & \\
Seongsan & & & & & \\
Spring & 27 & 26.1 & $-4.4 \pm 2.1$ & 0.267 & $0.966^{* *}$ \\
Summer & 36 & 50.9 & $-8.9 \pm 2.8$ & $0.393^{*}$ & $0.990^{* *}$ \\
Autumn & 25 & 15.8 & $-6.4 \pm 2.0$ & $0.401^{*}$ & $0.880^{* *}$ \\
Winter & 21 & 7.2 & $-6.7 \pm 2.2$ & 0.106 & $0.906^{* *}$ \\
\hline
\end{tabular}




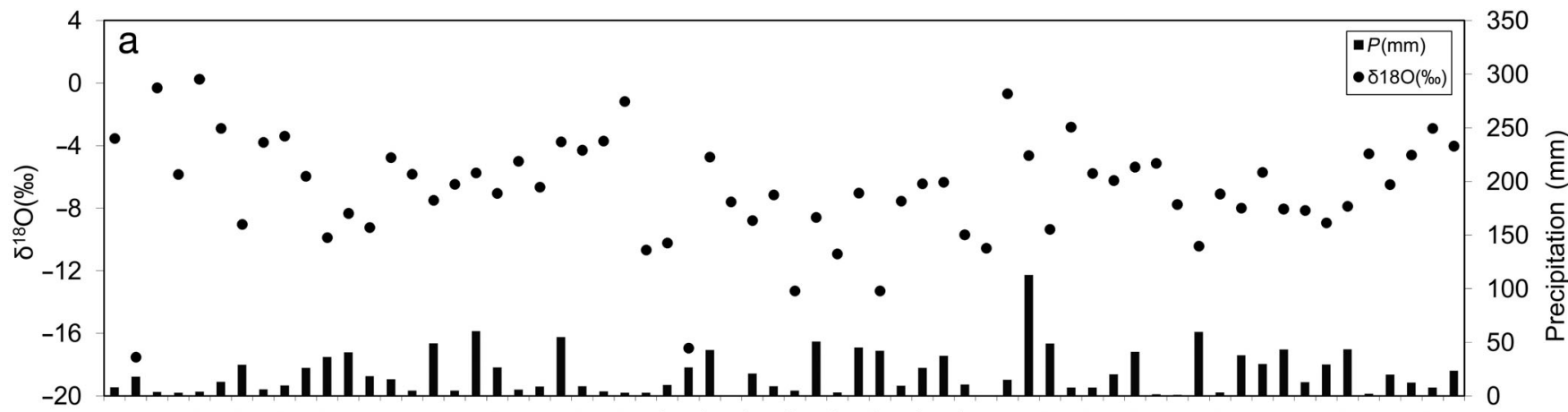

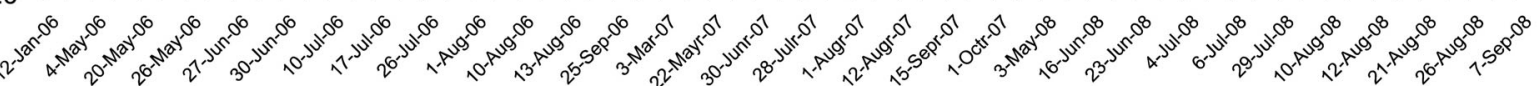

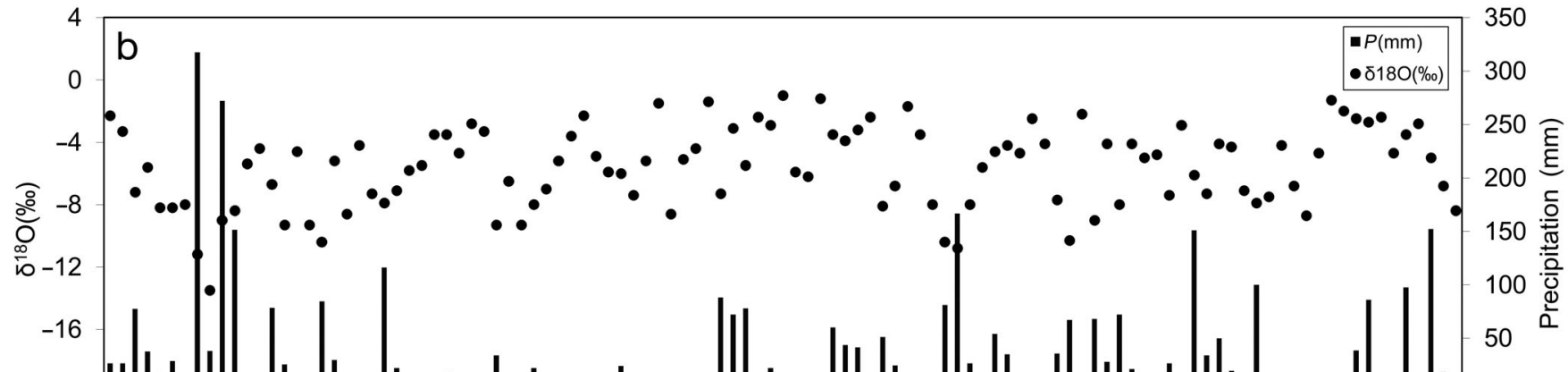

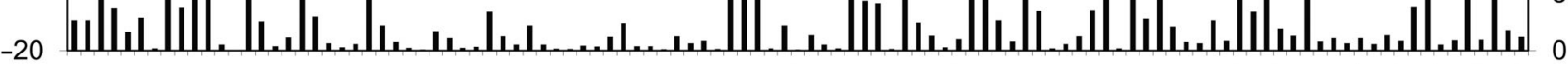

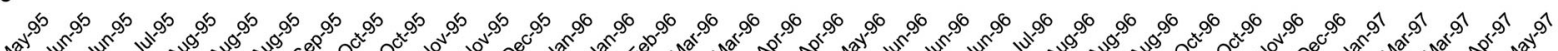

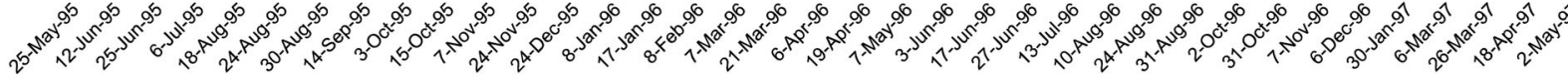

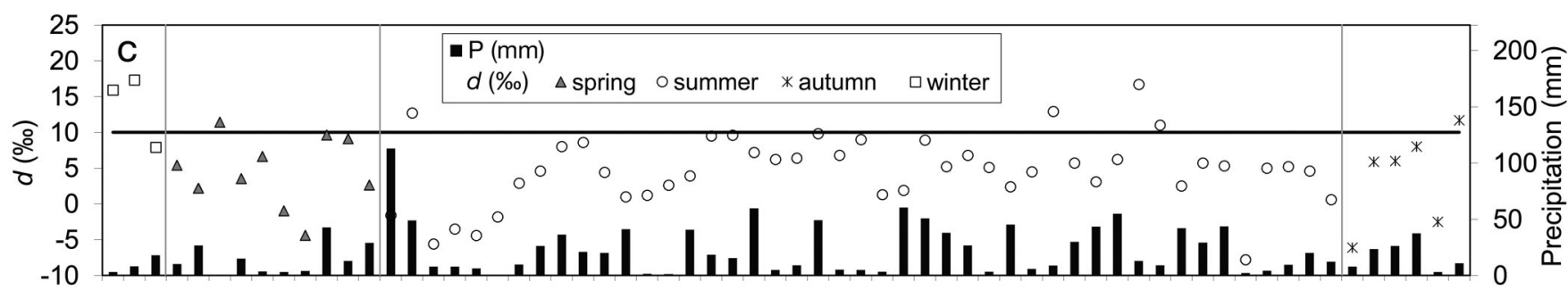

年
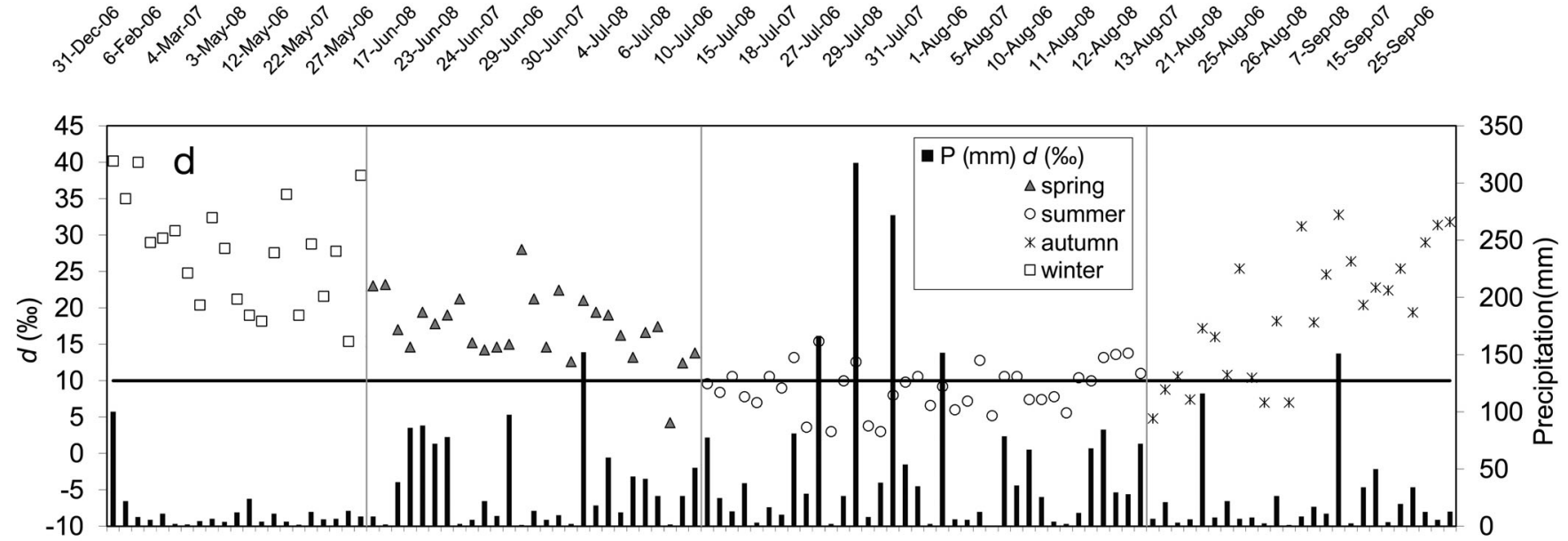

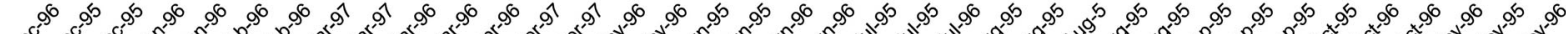

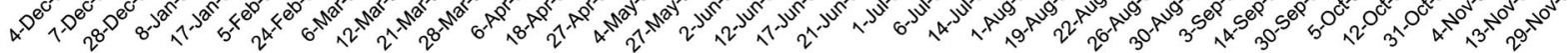

Fig. 3. Temporal variations of precipitation $\delta^{18} \mathrm{O}$ for (a) Beijing and (b) Seongsan; and deuterium excess $(d)$ in 4 seasons for (c) Beijing and (d) Seongsan. The horizontal line in (c) and (d) marks a value of $10 \%$, the global average value of $d$ in precipitation 

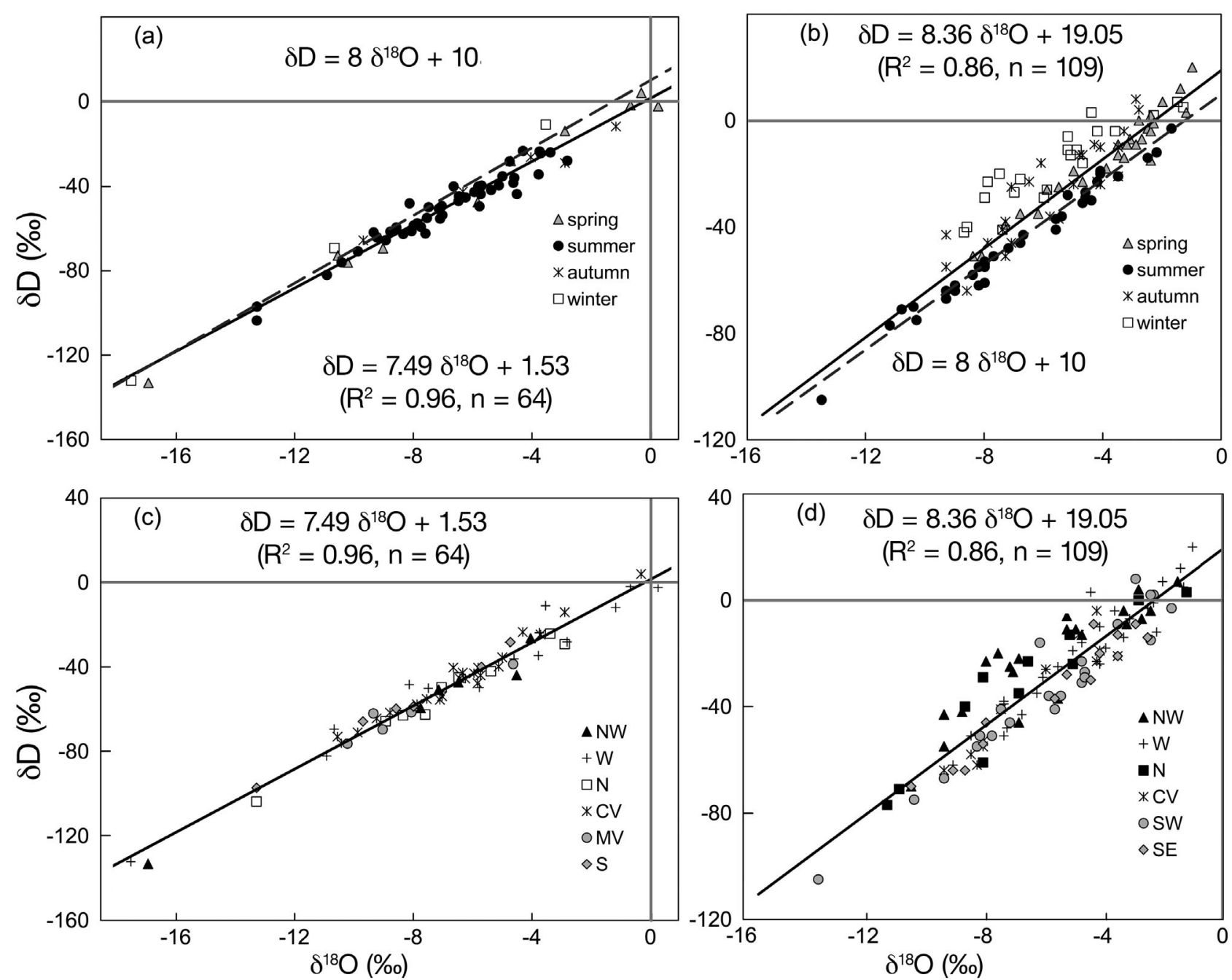

Fig. 4. Local meteoric water lines (solid lines) for ( $a, c)$ Beijing and (b, d) Seongsan. The global meteoric water line (dashed line) is given for reference. In (a) and (b), different symbols denote $\delta^{18} \mathrm{O}$ values for different seasons, while in (c) and (d), different symbols denote $\delta^{18} \mathrm{O}$ values for different air mass categories. Air mass categories as in Table 2

\subsubsection{Local meteoric water lines}

Based on 400 water samples collected globally from rivers, lakes, and precipitation, the nature of the isotopic relationship in meteoric waters (global meteoric water line, GMWL) was established as $\delta \mathrm{D}=$ $8 \delta^{18} \mathrm{O}+10$ (Craig 1961). Significant deviations from this line are observed in cases where the atmospheric circulation regime of a given area varies seasonally (e.g. Harvey \& Welker 2000, Vreča et al. 2006, Grassa et al. 2006, Liu et al. 2009, 2010b). In light of the stable isotopic composition in all of the precipitation events, the local meteoric water lines (LMWLs) for Beijing and Seongsan were established as $\delta \mathrm{D}=$ $7.49 \delta^{18} \mathrm{O}+1.53\left(\mathrm{R}^{2}=0.96, \mathrm{n}=64\right)$ and $\delta \mathrm{D}=8.36 \delta^{18} \mathrm{O}$ $+19.05\left(R^{2}=0.86, n=109\right)$, respectively. The $\delta D-\delta^{18} \mathrm{O}$ values for Beijing were generally located below the
GMWL (Fig. 4a), which indicates that the vapor composition deviated from the equilibrium composition (Dansgaard 1964), while a slope > 8 for Seongsan suggests a kinetic effect in the condensation (Fig. 4b).

For Beijing, the summer $\delta$ values varied little, while $\delta$ values for other seasons scattered to the upper or lower ranges of the LMWL. The 2 most depleted $\delta$ values occurred during the winter and early spring and reflected the high-latitude air mass (discussed below). Most of the enriched $\delta$ values represented spring precipitation. The winter months were rather dry for Beijing, with only around $10 \mathrm{~mm}$ of precipitation during the whole season. Although with the arrival of spring came an increase in precipitation, the atmosphere beneath the cloud base remained dry and far from saturated. Consequently, the evaporation of rain droplets during their fall resulted in the 
enrichment of the $\delta$ values in the residual rainwater. This evaporation effect gradually weakened as the rainy season progressed, with the $\delta$ values growing more depleted as rainfall increased (Liu et al. 2010b).

For Seongsan, points representing the winter and summer precipitation generally fell above and below the relevant LMWL, respectively (Fig. 4b). Data points for the transitional periods of spring and autumn distributed closely along the LMWL (Lee et al. 2003). In the winter, the cold air over the continent and the warm air over the South China Sea cause a pressure gradient, producing dry northeasterly winds that flow over southern Asia. This pressure gradient is reversed during the summer (Johnson \& Ingram 2004). Therefore, the distribution patterns for $\delta$ values corresponding to different seasons indicated opposite water vapor origins and circulation conditions.

\subsubsection{Deuterium excess}

The deuterium excess $(d$, in \%o), derived from $d=$ $\delta \mathrm{D}-8 \delta^{18} \mathrm{O}$ (Dansgaard 1964), is a measure of the deviation of a given data point from the GMWL. Globally, the average value of $d$ in precipitation is $10 \%$ (Craig 1961). Most of the data points for Beijing and Seongsan fell below or above the GMWL (Fig. 4a,b). For Seongsan, variations in $d$ according to the different seasons generally followed a ' $\mathrm{V}$ ' pattern, with higher values for $d$ during cold periods and lower values during hot periods (Fig. 3d). In temperate climates, seasonal fluctuations of $d$ are often observed, which is attributed to varying conditions in the source areas of the vapor (Araguás-Araguás et al. 2000). Higher $d$ values for both Beijing and Seongsan winter precipitation reflected kinetic fractionation under conditions involving low relative humidity. At Beijing, the relatively lower $d$ values for spring precipitation are attributed mainly to evaporation occurring during the fall of rain droplets (Barras \& Simmonds 2009). The $d$ values for Seongsan spring precipitation were much higher than those for Beijing. Although there were some reduced $d$ values for events involving small amounts of precipitation, the effect of the evaporation of rain droplets was not strong. This finding is likely because the atmosphere beneath the cloud base is more humid, as the amount of spring precipitation is 4 times larger at Seongsan $(P=281.6 \mathrm{~mm})$ than at Beijing $(P=66.6 \mathrm{~mm})$. During the summer, a $d$ value around $10 \%$ for Seongsan indicated its hot and humid intertropical oceanic moisture origin, with temperatures around $25^{\circ} \mathrm{C}$, moderate wind velocities, and relative humidity near $80 \%$ (Merlivat \& Jouzel 1979). The $d$ values for Beijing during the summer were generally below $10 \%$ and exhibited a larger range (Fig. 3c). Rain droplet evaporation was also notable in the light rainfall events that occurring during the summer (e.g. 24 June 2006 with $d=-4.36 \%$, $\delta^{18} \mathrm{O}=-3.78 \%$, and $P=6.2 \mathrm{~mm}$; and 5 July 2008 with $d=1.16 \%$, $\delta^{18} \mathrm{O}=-5.12 \%$, and $P=$ $1.4 \mathrm{~mm})$.

\subsection{Backward trajectory estimates}

The physical interpretation of the isotopic variations is complicated, as a single $\delta$ value reflects the integrated phase transition history of the respective water (Jacob \& Sonntag 1991). The determination of transport histories from meteorological conditions or through the calculation of trajectories improves inter-

Table 2. Meteorological conditions and $\delta^{18} \mathrm{O}($ mean $\pm \mathrm{SD})$ for different air mass categories. $T$ : temperature, $R H$ : relative humidity, $W S$ : wind speed, $S D$ : sunshine duration), $D T$ : dew point temperature. $P R F_{2}$ : air mass precipitation as a percentage of total precipitation amount

\begin{tabular}{|c|c|c|c|c|c|c|c|c|c|c|}
\hline & & Air mass & Events & $\delta^{18} \mathrm{O}_{p}(\%)$ & $P R F_{2}(\%)$ & $T\left({ }^{\circ} \mathrm{C}\right)$ & $R H(\%)$ & $W S\left(\mathrm{~m} \mathrm{~s}^{-1}\right)$ & $S D(\mathrm{~h})$ & $D T\left({ }^{\circ} \mathrm{C}\right)$ \\
\hline \multirow[t]{6}{*}{ Beijing } & NW & Northwest & 6 & $-9.20 \pm 4.7$ & 5.9 & 21.9 & 69 & 2.4 & 5.4 & - \\
\hline & $\mathrm{W}$ & West & 15 & $-5.99 \pm 4.8$ & 15.9 & 18.8 & 73 & 2.2 & 3.4 & - \\
\hline & NNW & North-northwest & 9 & $-8.18 \pm 3.1$ & 14.6 & 25.3 & 74 & 2.0 & 3.9 & - \\
\hline & $\mathrm{S}$ & South & 6 & $-7.23 \pm 3.0$ & 12.8 & 23.1 & 82 & 2.1 & 0.5 & - \\
\hline & MV & Marine vicinity & 5 & $-6.94 \pm 2.2$ & 17.6 & 18.0 & 82 & 2.1 & 0.8 & - \\
\hline & $\mathrm{CV}$ & Continental vicinity & y 23 & $-7.28 \pm 2.4$ & 33.2 & 22.8 & 76 & 2.2 & 2.2 & - \\
\hline \multirow[t]{6}{*}{ Seongsan } & NW & Northwest & 21 & $-6.7 \pm 2.6$ & 12.2 & - & 5.4 & 11.5 & - & 10.4 \\
\hline & W & West & 29 & $-5.4 \pm 2.2$ & 26.3 & - & 12.4 & 6.4 & - & 15.9 \\
\hline & $\mathrm{N}$ & North-northwest & 11 & $-10.3 \pm 3.1$ & 15.5 & - & 8.9 & 7.6 & - & 13.7 \\
\hline & $\mathrm{CV}$ & Continental vicinity & y 12 & $-7.3 \pm 2.1$ & 10.6 & - & 17.3 & 6.6 & - & 20.7 \\
\hline & SW & Southwest & 22 & $-6.9 \pm 2.9$ & 15.8 & - & 16.3 & 5.2 & - & 20.2 \\
\hline & $\mathrm{SE}$ & Southeast & 14 & $-7.4 \pm 2.6$ & 19.6 & - & 19.3 & 5.6 & - & 22.9 \\
\hline
\end{tabular}



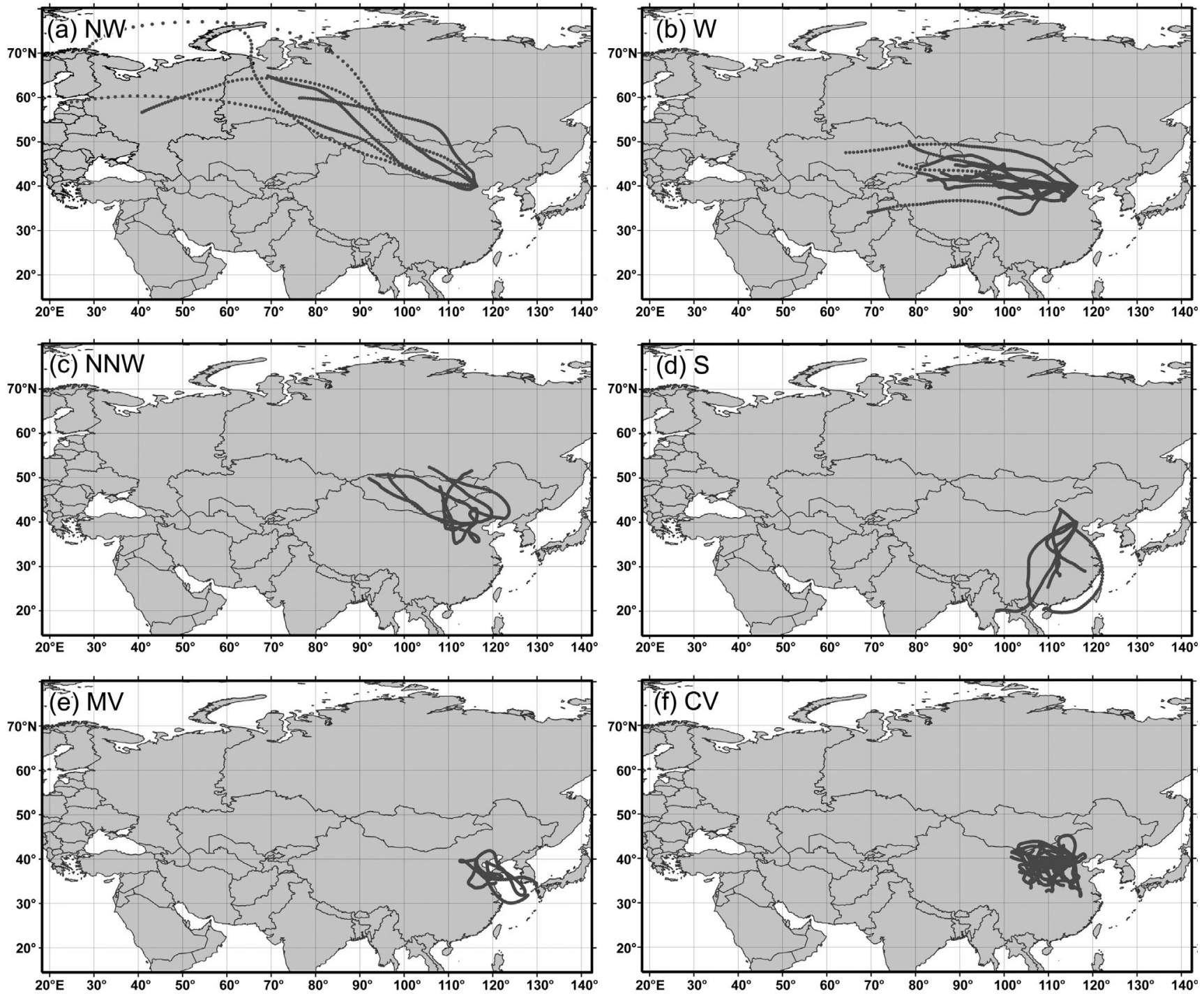

Fig. 5. Air masses arriving at Beijing during 2006-2008, classified by 96 h backward trajectories. Each line consists of 96 dots; spacing of dots indicates speed of the air mass. Air mass categories as in Table 2

pretive explanations. For each precipitation event at Beijing (Fig. 5) and Seongsan (see Figs. 8 \& 9), the $96 \mathrm{~h}$ backward trajectories of the air masses arriving at $3000 \mathrm{~m}$ agl were categorized into 6 main groups according to the moisture origins, paths, altitudes, and speeds of transport (Shan et al. 2009).

\subsubsection{Beijing}

(1) Northwestern (NW), high-latitude air masses came from northwest of the European continent and the Arctic Ocean, subsequently passing over Mongolia. These air masses were the driest (with the percentage of the category precipitation amount with total precipitation amount, $P R F_{2}=5.9 \%$ and $\mathrm{RH}=$
$69 \%$ ). High-latitude origins and long transport paths led to a continuous depletion of heavy isotope component, resulting in the lowest $\delta^{18} \mathrm{O}_{p}$ value $(-9.20 \%$ o) among the 6 categories (Table 2). One of the 2 lowest $\delta^{18} \mathrm{O}$ values (4 March 2007, $\delta^{18} \mathrm{O}=-16.93 \%$ ), located at the bottom of the Beijing LMWL (discussed in Section 4.1.2.) belonged to this category.

(2) Western (W) air masses originated from the inner-western Eurasian continent, subsequently passing over arid/semi-arid northwestern China with almost horizontal transport paths at different speeds. A total of 15 events belonged to this category $\left(P R F_{2}=\right.$ $15.9 \%$ ), making it the second most-frequent air mass path. Air masses belonging to this category could generally be divided into those arriving in the winter (with very low $\delta$ values) and those arriving in the sum- 

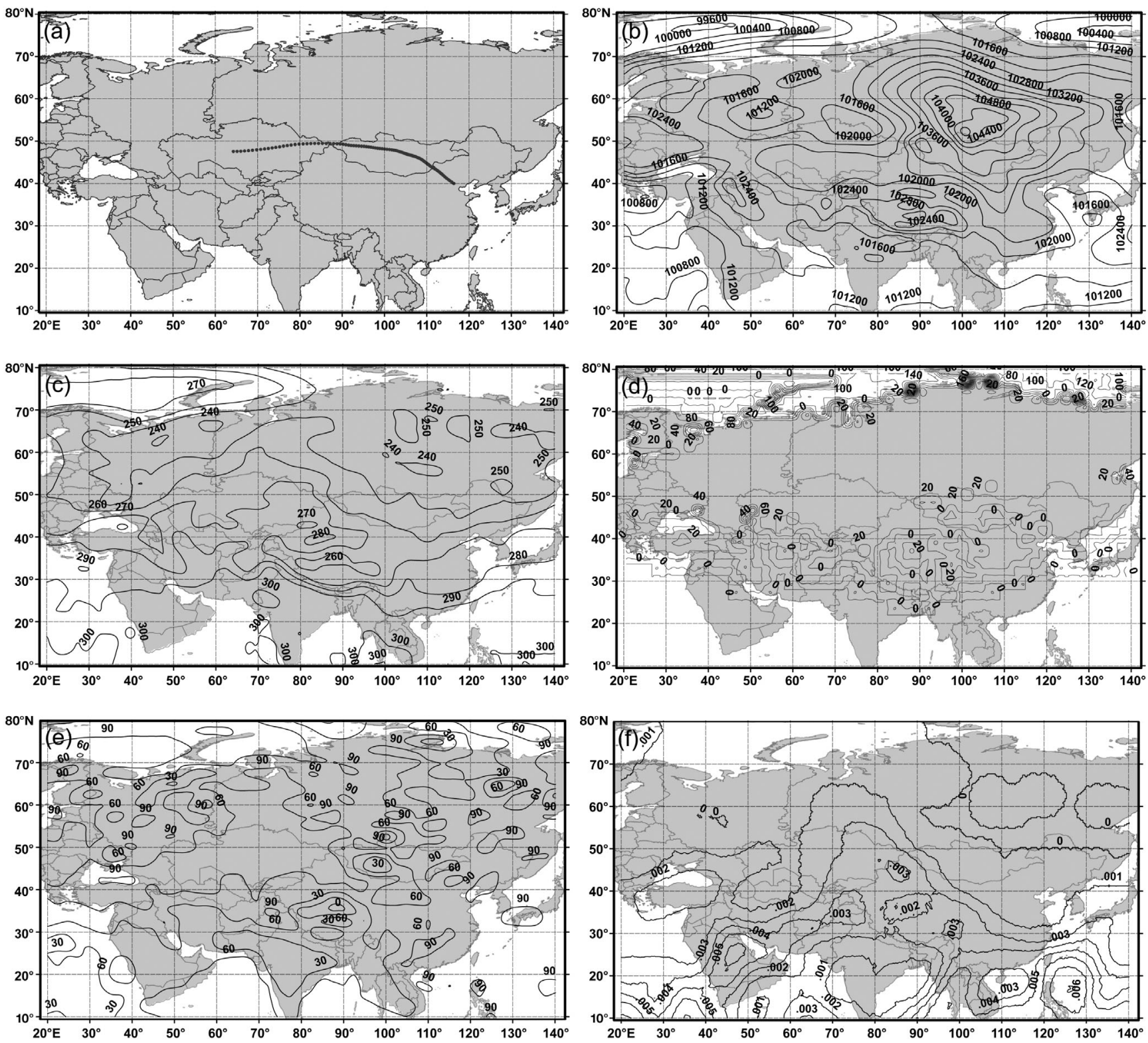

Fig. 6. Meteorological conditions for 6 February 2006: (a) air mass backward trajectory for 96 h, (b) sea level pressure (Pa), (c) surface temperature (K), (d) water equivalent of accumulated snow depth $\left(\mathrm{kg} \mathrm{m}^{-2}\right)$, (e) relative humidity (\%), and (f) specific humidity $\left(\mathrm{kg} \mathrm{kg}^{-1}\right)$

mer (with high $\delta$ values). Each of the 3 snow events during the observation period belonged to this category (see the top trajectory for 6 February 2006, the bottom trajectory for 12 January 2006, and an upper one for 31 December 2006; Fig. 5b). Under the control of the Mongolia High in the winter (Fig. 6b), the north-westerly winds brought dry, high-latitude continental air masses. The low air temperature ( 250 to $260 \mathrm{~K}$, or -23.2 to $\sim-13.2^{\circ} \mathrm{C}$, Fig. 6c) and thick snow cover ( $20 \mathrm{~mm}$, Fig. $6 \mathrm{~d}$ ) meant that there was little energy available for evaporation or sublimation of snow (Lee et al. 2003). As such, few air masses were picked up along the transport path and the specific humidity remained stable (1 to $2 \mathrm{~g} \mathrm{~kg}^{-1}$, Fig. 6f). After a long transport, the $\delta$ values tended to be rather depleted upon arrival at the precipitation area (e.g. $\delta^{18} \mathrm{O}=$ $-17.51 \%$ for the snow event of 6 February 2006; located at the bottom of the LMWL). Except for the 3 snow events, all precipitation events associated with this category appeared from May to August and featured relatively high $\delta^{18} \mathrm{O}$ concentrations. Evaporation and isotopic exchange of the air masses with the relatively hot and dry ambient atmosphere may occur along the trajectory, which leads to the enrichment of 

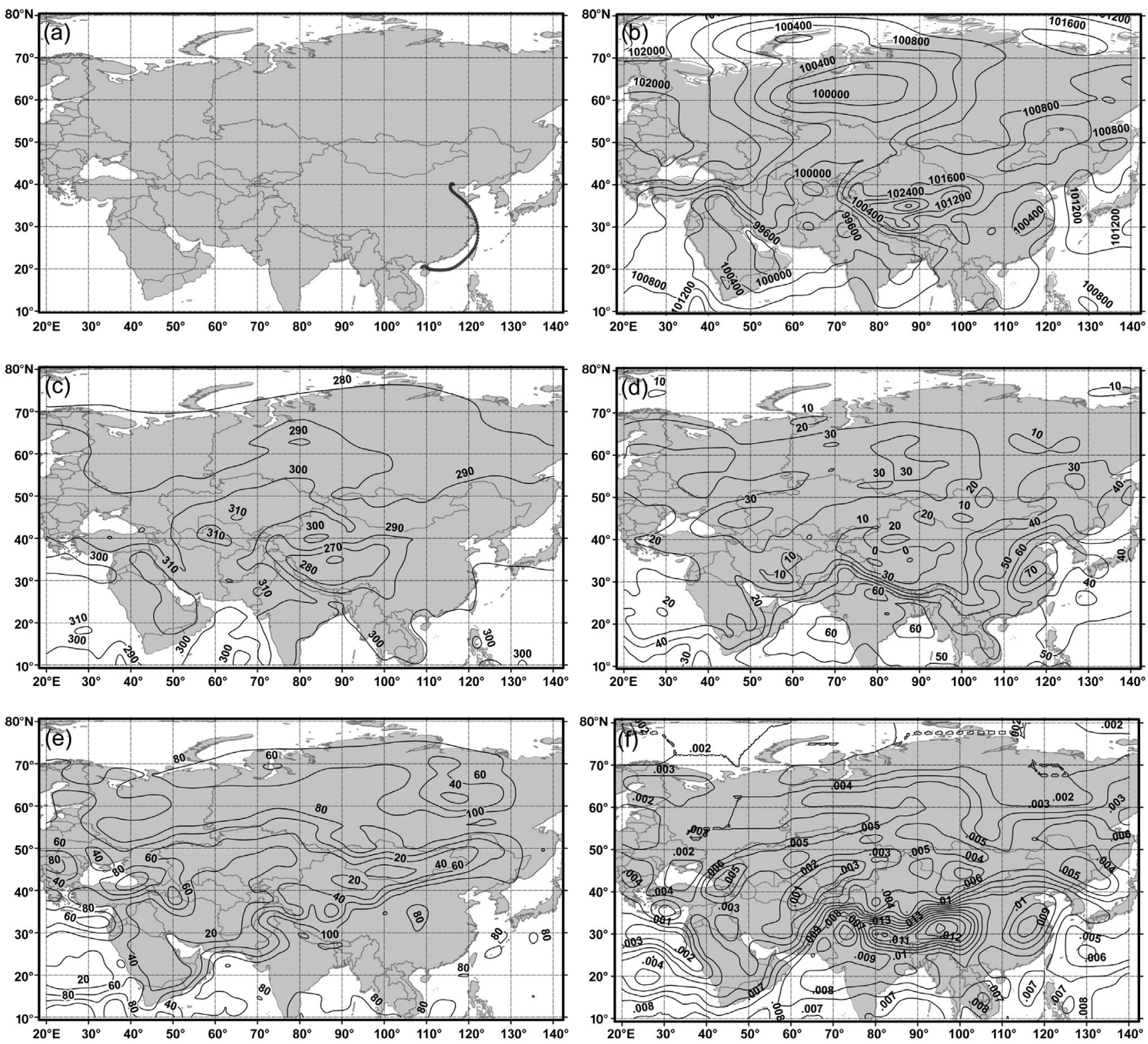

Fig. 7. Backward trajectory of air mass and the meteorological conditions for 31 July 2008: (a) air mass backward trajectory for $96 \mathrm{~h}$, (b) sea level pressure (Pa), (c) surface temperature $(\mathrm{K})$, (d) precipitable water content $\left(\mathrm{kg} \mathrm{m}^{-2}\right)$, (e) relative humidity (\%), and (f) specific humidity $\left(\mathrm{kg} \mathrm{kg}^{-1}\right)$

$\delta$ values of the residual water and the final rainfall. A rather enriched $\delta^{18} \mathrm{O}$ is particularly characteristic of the summer precipitation in arid/semi-arid northwestern China (Liu et al. 2009).

(3) North-northwestern (NNW) continental air masses originated from the north, the northwest, or from central Mongolia. The temperatures for this category were the highest, given that all of the 7 precipitation events belonging to this category occurred from June to September. Typical meteorological conditions for this type involved low wind speeds and extended periods of sunshine. All of the NW, W, and NNW categories had high- or mid-latitude continental origins. They shared some similar meteorological characteristics, such as low amounts of precipitation, low relative humidity, and long periods of sunshine.

(4) Southern (S) air masses came from the south, mainly passing over the inland area of southern China. Rainfall events for this category occurred mostly in July. When the summer came, the Mongolia High, centered over the Asian continent, gave way to an area of low pressure (Fig. 7b). The high 
pressures located over the ocean forced warm and humid moisture to the continent (Fig. 7d). For the rainfall event on 31 July 2008 (Fig. 7a), a continuous rainout process and some evaporated water likely picked up along the trajectory (the specific humidity decreased from $\sim 9$ to $7 \mathrm{~g} \mathrm{~kg}^{-1}$, Fig. $7 \mathrm{f}$ ) resulted in the depletion of heavy isotope $\left(\delta^{18} \mathrm{O}=-7.99 \%\right)$.

(5) Marine vicinity (MV) air masses had no defined paths, being located at mid-latitudes and moving slowly in short paths or looping trajectories over the marine vicinity. Only 5 events were attributed to this group, and the $P R F_{2}$ was $17.6 \%$. While the MV and $\mathrm{S}$ categories shared nearly identical meteorological conditions, such as little sunshine, moderate wind speeds, and comparatively high relative humidity (Table 2), there was still a slightly lower value in $\delta^{18} \mathrm{O}_{p}$ for $\mathrm{S}$ $(-7.23 \%$ o) than for MV $(-6.94 \%)$, a fact that may be attributed to the longer transport paths taken by the S-type masses along the continental regions.

(6) Continental vicinity (CV) air masses were similar to MV but had trajectories that looped over the continental vicinity. It was the most frequent type of path, i.e. it was the type most frequently associated with the summer rainfall in Beijing. Of the 23 events belonging to this category, the majority occurred during July and August, with June, September, and May featuring many of the others. Meteorological conditions for this category typically involved moderate temperature, relative humidity, wind speed, and sunshine duration (Table 2). The $\delta^{18} \mathrm{O}_{p}$ was $-7.28 \%$, which falls beween the values for air masses with continental and marine origins. Air masses could originate either from marine locations $96 \mathrm{~h}$ before or from high-latitudinal, inner-continental regions. The trajectory for 18 September 2007 represented moisture originating in the Pacific Ocean, which was transported by the No. 0712 severe typhoon and No. 0713 super typhoon, which occurred from 11 to 18 September 2007 and 15 to 20 September 2007, respectively.

\subsubsection{Seongsan}

Typical meteorological conditions for precipitation events with air masses originating from the NW, N, and SW have been detailed by Lee et al. (2003). Below, the primary focus will be on categorizing the air masses for precipitation events at Seongsan.

(1) NW high-latitude moisture came from northwest of the European continent and from the Mediterranean. The 21 events accounted for $12.2 \%$ of the total precipitation, as most of this precipitation oc- curred during the late autumn, winter, and early spring, when the conditions were relatively dry. Though featuring the longest paths and the lowest temperature, the $\delta^{18} \mathrm{O}_{p}(-6.7 \%)$ associated with this type was not low, probably because only 2 precipitation events belonging to this category fell in the summer months, when the Asian monsoon was responsible for the heaviest rainfall and the most depleted $\delta^{18} \mathrm{O}$ values (Bhattacharya et al. 2003, Aggarwal et al. 2004, Vuille et al. 2005, Liu et al. 2010a). Typically, the relatively high $d$ values for NW air masses indicated relatively low humidity during the moisture formation (Lee et al. 2003).

(2) W air masses bore similarities to those associated with Beijing but featured even longer paths. This type was most frequently responsible for precipitation, with 29 events altogether. Most of the precipitation events happened in the spring, followed by the autumn, summer, and winter. The spring W-type events accounted for $57.9 \%$ of the total category rainfall $\left(P R F_{2}=26.3 \%\right)$. The value of $\delta^{18} \mathrm{O}_{p}(-5.4 \%)$ was highest in relation to this type, possibly due to the evaporation of the raindrops during their fall to the ground or the fact that no precipitation events associated with this category occurred in July, which usually featured the lowest $\delta$ values.

(3) $\mathrm{N}$ continental air masses originated mainly in Siberia. Although there were only 11 events associated with this category, it was responsible for precipitation in all 4 seasons. Typical meteorological conditions for this category included moderate wind velocity and relatively low temperature. Taking all events into account, this type seemed to feature the most depleted $\delta^{18} \mathrm{O}_{p}(-10.3 \%)$. In reality, however, 2 of the heaviest rainfall events, occurring on 21 June $1996\left(\delta^{18} \mathrm{O}=-10.8 \%, P=166.5 \mathrm{~mm}\right)$ and 1 July 1995 $\left(\delta^{18} \mathrm{O}=-11.2 \%\right.$, $\left.P=317.5 \mathrm{~mm}\right)$ represented the largest contributions. If the impact of these events were ignored, the value for $\delta^{18} \mathrm{O}_{p}$ would be $-6.5 \%$, which is close to the values associated with the NW and $\mathrm{W}$ categories.

(4) CV air masses featured the shortest paths and the lowest $P R F_{2}(10.6 \%)$. The precipitation linked to this category occurred mostly in the summer. No spring precipitation was associated with this category. In a situation similar to that noted above for the NNW type, 1 event in this category, occurring on 22 July $1995\left(\delta^{18} \mathrm{O}=-8.4 \%\right.$, $\left.P=151.5 \mathrm{~mm}\right)$, was responsible for a reduced $\delta^{18} \mathrm{O}_{p}$. If this event were ignored, the $\delta^{18} \mathrm{O}_{p}$ for the category would be $-6.6 \%$.

(5) SW air masses originated from low-latitude regions of southwest China and the adjacent South China Sea. The $\delta^{18} \mathrm{O}_{p}(-6.9 \%)$ value for this type is 
low because most of the events occurred in July and August, when the Asian monsoon was responsible for rainfall characterized by depleted $\delta^{18} \mathrm{O}$.

(6) SE air masses had southeast marine origins. The mean temperature of this category was the highest of any category, but $\delta^{18} \mathrm{O}_{p}$ was the most depleted $(-7.4 \%)$. About $81 \%$ of all precipitation events associated with this category occurred in the summer, and none in winter. The low $d$ values for this category reflected the characteristics of the hot and humid North Pacific (Lee et al. 2003).

The 6 air mass categories for Seongsan tended to appear at particular times of the year (e.g. NW: late autumn, winter, and early spring, Fig. 8; W: mostly spring; CV: mostly summer but not spring; SW and SE: summer; and N: all seasons). Thus, the categories linked with summer precipitation, mainly SE, SW, and CV (Fig. 9), were less varied than those associated with summer precipitation in Beijing (Fig. 5). The multiple types of precipitation air masses found in Beijing were probably also responsible for its comparatively larger ranges for $d$ (discussed in Section 4.1.3.). Furthermore, distinctions between the continental and marine origins of the moisture were determined from LMWL for Seongsan (Fig. 4d), with the data points for NW and $\mathrm{N}$ categories generally located above the line and those for SW and SE categories situated below the line.
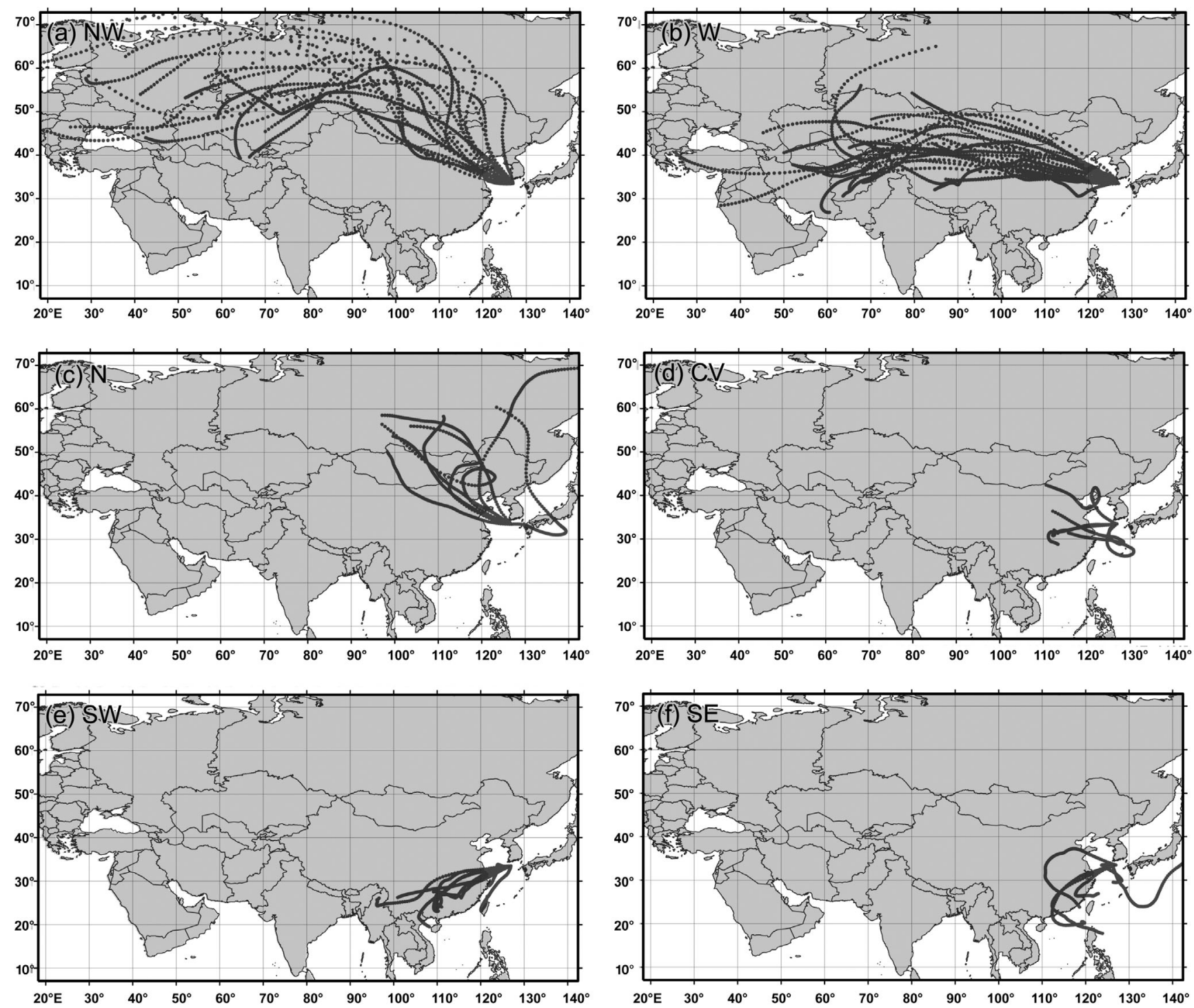

Fig. 8. Air masses arriving at Seongsan during spring, autumn, and winter of 1995-1997, classified by 96 h backward trajectories. Air mass categories as in Table 2 

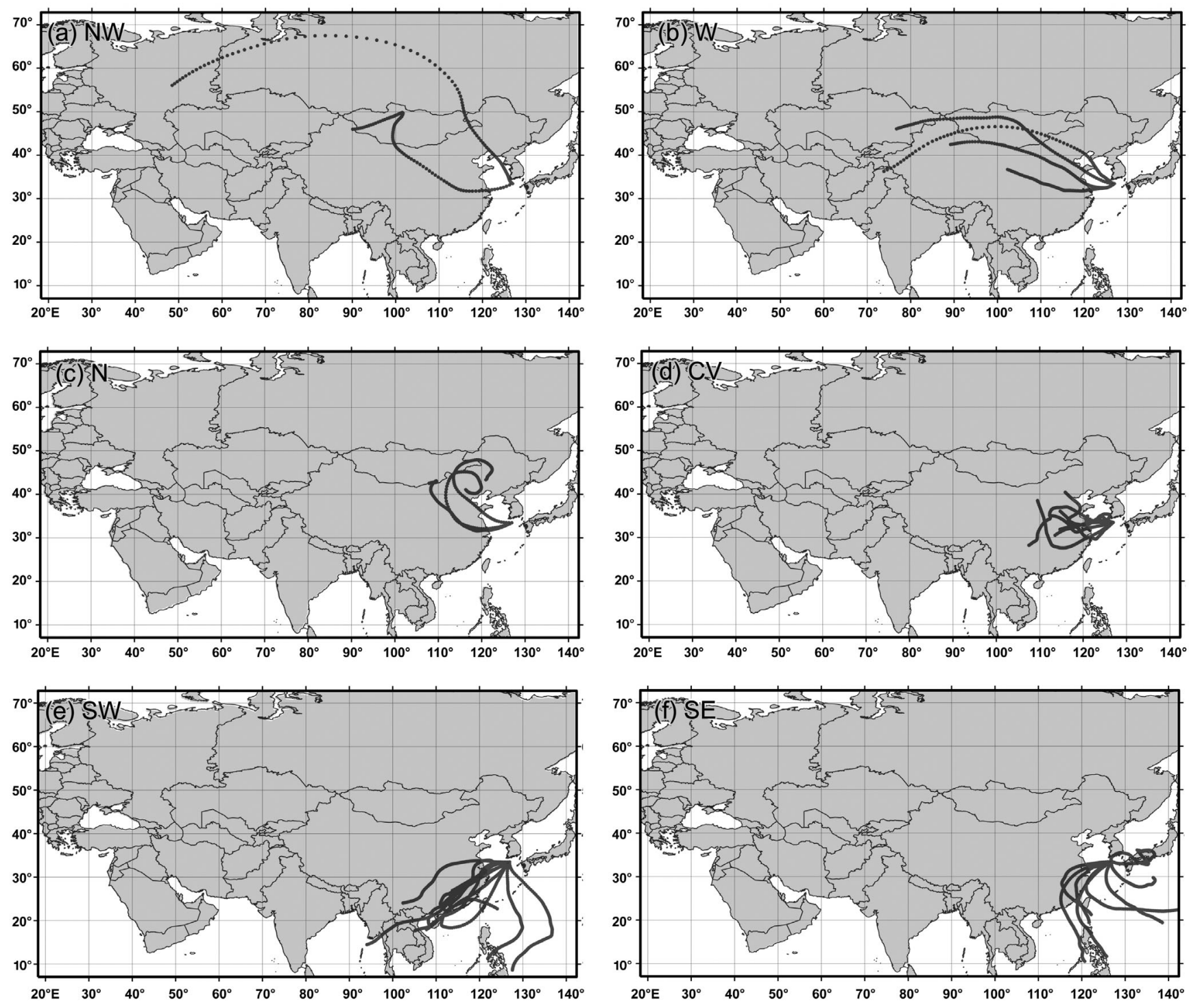

Fig. 9. Air masses arriving at Seongsan in summer of 1995-1997, classified by $96 \mathrm{~h}$ backward trajectories. Air mass categories as in Table 2

\subsection{Climatic controls on $\delta^{18} \mathrm{O}$}

The investigation of isotopic information contained in archives such as ice cores (Bradley et al. 2003), lake sediments (Junge \& Böttger 1994), tree rings (Managave et al. 2010), and speleothems (McDermott 2004), is one method for the quantitative reconstruction of paleoclimate. It is first necessary to determine how the isotopes associated with modern precipitation relate to the current climate conditions (Jacob \& Sonntag 1991) because the isotopic composition contained in precipitation generally reflects synthetic synoptic conditions before being recorded. Regression equations based on the presently ob- served spatial relation between the mean annual temperature and the isotope ratio in precipitation in high latitudes have been used to derive a history of the temperature changes experienced at the site of a given ice core (Dansgaard et al. 1982, Jouzel et al. 1987). Such applications, however, usually encounter problems at middle and low latitudes, especially in the Asian monsoon regions, because both the temperature and precipitation are highest in the summer, and the temperature effect and the amount effect partially cancel each other out (Johnson \& Ingram 2004). In the present study, simple linear correlations between $\delta / T$ and $\delta / P$ were not high at either site during any point of the observation period (Table 1 ). In addi- 
tion to the reason noted above, the meteorological conditions associated with different air mass trajectories may also be responsible.

To detect the main meteorological controls pertaining to different air masses, regularly observed surface meteorological variables associated with precipitation sampling sites were analyzed with the multiple stepwise regression method. Multiple regressions allow for the simultaneous calculation of several physical parameters (Liu et al. 2010b). Potential partial correlations showed that sometimes a quadratic or logarithmic solution was in closer agreement with the $\delta^{18} \mathrm{O}$. Therefore, non-linear stepwise regression was adopted. For Beijing, the daily minimum temperature and precipitation amount more frequently factored into the equation (Table 3 ). This finding was likely because most of the precipitation samples had been collected in the summer, when the temperature and precipitation amounts could be equally important for the $\delta^{18} \mathrm{O}$ variations at this site (Liu et al. 2010a). Furthermore, the surface air temperature tended to reach a minimum when the precipitation event happened. Therefore, instead of daily mean air temperature, daily minimum temperature played a more dominant role. Most of the regression models could predict the $\delta^{18} \mathrm{O}$ well. The established regressions for the $\mathrm{S}, \mathrm{MV}$, and NW categories were able to explain more than $90 \%$ of the observation $\delta^{18} \mathrm{O}$ variations. Equations for the $\mathrm{W}$ and NNW categories captured over $80 \%$ of the observed $\delta^{18} \mathrm{O}$ variations; however, with only the variable of precipitation amount selected, the equation for the CV category captured less than $40 \%$ of the $\delta^{18} \mathrm{O}$ variation.
In contrast to Beijing, where regression models usually selected 2 to 5 controlling parameters, the precipitation amount seemed to be the predominant factor for most air masses arriving at Seongsan. With the exception of the CV type, the equations for all categories selected this factor. It was particularly important for the NW, N, SW, and SE categories, in which the precipitation amount was the main impact factor. In comparison, regression models established for each category in Seongsan captured fewer $\delta^{18} \mathrm{O}$ variations (about $50 \%$ ) than those for Beijing. The logarithmic $\delta / P$ relationships describe the control of the precipitation amount on the isotope content better than the pure linear relationships suggested by Lee et al. (2003).

\section{SUMMARY AND CONCLUSIONS}

The continental Beijing site had larger ranges in $\delta \mathrm{D}$ and $\delta^{18} \mathrm{O}$ than the island Seongsan site. In Seongsan, most of the depleted $\delta^{18} \mathrm{O}$ values were in phase with the heaviest precipitation events; in Beijing, however, this was not the case. The established LMWLs, $\delta \mathrm{D}=7.49 \delta^{18} \mathrm{O}+1.53$ and $\delta \mathrm{D}=8.36 \delta^{18} \mathrm{O}+19.05$, reflected periodically dry conditions in Beijing, and the kinetic effect in the condensation process in Seongsan. The lower $d$ values for spring and summer precipitation could be mainly attributed to the evaporation occurring during the fall of rain droplets into the relatively dry atmosphere beneath the cloud base. The ' $\mathrm{V}$ ' type of the $d$ pattern for Seongsan revealed variations in vapor origins. Based on the HYSPLIT

Table 3. Non-linear stepwise regressions of $\delta^{18} \mathrm{O}$ for each air mass category in Beijing and Seongsan. Variables for equations, $P$ : precipitation amount (mm), $T$ : surface air temperature $\left({ }^{\circ} \mathrm{C}\right), T_{\text {max }}$ : maximum surface air temperature $\left({ }^{\circ} \mathrm{C}\right), T_{\min }:$ minimum surface air temperature $\left({ }^{\circ} \mathrm{C}\right), R H$ : relative humidity $(\%), V p$ : vapor pressure $(\mathrm{hPa}), W S$ : wind speed $\left(\mathrm{m} \mathrm{s}^{-1}\right), S D$ : sunshine duration $(\mathrm{h})$. Air mass categories as in Table 2

\begin{tabular}{|lllr|}
\hline & Air mass & Regression equations & $R$ \\
\hline Beijing & All & $\delta^{18} \mathrm{O}=0.223 T_{\min }-0.279 \mathrm{SD}-14.797 \log R H+17.495$ & 0.49 \\
& NW & $\delta^{18} \mathrm{O}=7.417 \log T_{\min }+0.206 \mathrm{Vp}-222.503$ & 0.98 \\
W & $\delta^{18} \mathrm{O}=-0.023 T^{2}+0.86 T-0.592 S D-8.792$ & 0.79 \\
NNW & $\delta^{18} \mathrm{O}=0.02 T_{\min }^{2}-0.184 P-11.244$ & 0.84 \\
CV & $\delta^{18} \mathrm{O}=-0.049 P-5.482$ & 0.38 \\
MV & $\delta^{18} \mathrm{O}=0.05 P-0.364 S D+0.031 T_{\min }-0.004 W S^{2}-10.869$ & 0.98 \\
S & $\delta^{18} \mathrm{O}=7.172 \log P-79.568 \log R H-0.185 T_{\max }-0.588 W+0.048 T+139.431$ & 0.48 \\
Seongsan & & 0.40 \\
NW & $\delta^{18} \mathrm{O}=-1.723 \log P+0.055 V p-59.479$ & 0.53 \\
W & $\delta^{18} \mathrm{O}=-1.818 \log P-4.047$ & 0.75 \\
N & $\delta^{18} \mathrm{O}=-1.521 \log P+0.018 W S^{2}-3.622$ & 0.67 \\
CV & $\delta^{18} \mathrm{O}=-3.389 \log P-2.789$ & 0.51 \\
SW & $\delta^{18} \mathrm{O}=0.176 V p-183.82$ & 0.51 \\
SE & $\delta^{18} \mathrm{O}=-2.68 \log P-2.853$ & \\
\hline
\end{tabular}


model, $96 \mathrm{~h}$ backward trajectories of air masses arriving at $3000 \mathrm{~m}$ agl for each precipitation event at the 2 sites were calculated. Six categories were obtained for each site, based on the moisture origins, paths, latitudes, and speeds of transport. All categories (NW, W, NNW, S, MV, and CV) were represented in the summer precipitation in Beijing, while only the SW, $\mathrm{SE}$, and CV categories were represented in the summer precipitation in Seongsan. Dominant meteorological controlling factors for the various categories were also identified through a non-linear stepwise regression method. Regressions for Beijing selected 2 to 5 factors, while the precipitation amount emerged as the predominant controlling factor for Seongsan.

Acknowledgements. This work was supported by the Key Program of the National Natural Science Foundation of China (No. 40830636) and the State Basic Research Development Program (973 Program) of China (No. 2010CB428805). We thank the China Meteorological Data Sharing Service System and the NOAA Satellite and Information Service for providing the meteorological data. We gratefully acknowledge the NOAA Air Resources Laboratory for providing the HYSPLIT model. We also thank L. Ai of the Institute of Atmospheric Physics at the Chinese Academy of Sciences for valuable advice on the HYSPLIT model analysis.

\section{LITERATURE CITED}

Aggarwal PK, Fröhlich K, Kulkarni KM, Gourcy LL (2004) Stable isotope evidence for moisture sources in the Asian summer monsoon under present and past climate regimes. Geophys Res Lett 31:L08203 doi:10.1029/2004 GL019911

Araguás-Araguás L, Froehlich K, Rozanski K (2000) Deuterium and oxygen-18 isotope composition of precipitation and atmospheric moisture. Hydrol Process 14: 1341-1355

Barras VJI, Simmonds I (2008) Synoptic controls upon $\delta^{18} \mathrm{O}$ in southern Tasmanian precipitation. Geophys Res Lett 35:L02707 doi:10.1029/2007GL031835

> Barras V, Simmonds I (2009) Observation and modelling of stable water isotopes as diagnostics of rainfall dynamics over southeastern Australia. J Geophys Res 114:D23308 doi:10.1029/2009JD012132

> Bhattacharya SK, Froehlich K, Aggarwal PK, Kulkarni KM (2003) Isotopic variation in Indian Monsoon precipitation: records from Bombay and New Delhi. Geophys Res Lett 30:2285 doi:10.1029/2003GL018453

Bradley RS, Vuille M, Hardy D, Thompson LG (2003) Low latitude ice cores record Pacific sea surface temperature. Geophys Res Lett 30:1174 doi:10.1029/2002GL016546

Craig H (1961) Isotopic variations in meteoric waters. Science 133:1702-1703

$>$ Dansgaard W (1964) Stable isotopes in precipitation. Tellus 16:436-468

Dansgaard W, Clausen HB, Gundestrup N, Hammer CU, Johnsen SJ, Kristinsdottir PM, Reeh N (1982) A new Greenland ice core. Science 218:1273-1277

Draxler RR, Rolph GD (2003) HYSPLIT (HYbird Single-Parti- cle Lagrangian Integrated Trajectory) Model. NOAA Air Resources Laboratory, Silver Spring, MD. Available at www.arl.noaa.gov/ready/hysplit4.html

Gedzelman SD, Lawrence JR (1982) The isotopic composition of cyclonic precipitation. J Appl Meteorol 21: 1385-1404

Grassa F, Favara R, Valenza M (2006) Moisture source in the Hyblean Mountains region (south-eastern Sicily, Italy): evidence from stable isotopes signature. Appl Geochem 21:2082-2095

Guo X, Fu D, Wang J (2006) Mesoscale convective precipitation system modified by urbanization in Beijing City. Atmos Res 82:112-126

Harvey FE, Welker JM (2000) Stable isotopic composition of precipitation in the semi-arid north-central portion of the US Great Plains. J Hydrol (Amst) 238:90-109

Huang R, Zhou L, Chen W (2003) The progresses of recent studies on the variabilities of the East Asian monsoon and their causes. Adv Atmos Sci 20:55-69

Jacob H, Sonntag C (1991) An 8-year record of the seasonal variation of ${ }^{2} \mathrm{H}$ and ${ }^{18} \mathrm{O}$ in atmospheric water vapor and precipitation at Heidelberg, Germany. Tellus Ser B Chem Phys Meteorol 43:291-300

Johnson KR, Ingram BL (2004) Spatial and temporal variability in the stable isotope systematics of modern precipitation in China: implications for paleoclimate reconstructions. Earth Planet Sci Lett 220:365-377

> Jouzel J, Lorius C, Petit JR, Genthon C, Barkov NI, Kotlyakov VM, Petrov VM (1987) Vostok ice core: a continuous isotopic temperature record over the last climatic cycle (160, 000 years). Nature 329:403-408

$>$ Junge FW, Böttger T (1994) Isotope geochemical studies on carbonates of quaternary glacio-lacustrine lake sediments as indicators of paleoenvironment. Isotopes Environ Health Stud 30:9-21

Kalnay E, Kanamitsu M, Kistler R, Collins W and others (1996) The NCEP/NCAR 40-year reanalysis project. Bull Am Meteorol Soc 77:437-470

Kwon HJ (1985) Natural geography. Bummoonsa, Seoul (in Korean)

- Lawrence JR, Gedzelman SD (1996) Lower stable isotope ratios of tropical cyclone rains. Geophys Res Lett 23: $527-530$

Lawrence JR, Gedzelman SD, White JWC, Smiley D, Lazov $P$ (1982) Storm trajectories in eastern US D/H isotopic composition of precipitation. Nature 296:638-640

Lee KS, Grundstein AJ, Wenner DB, Choi MS, Woo NC, Lee DH (2003) Climatic controls on the stable isotopic composition of precipitation in Northeast Asia. Clim Res 23: $137-148$

Lee LYL, Kwok RCW, Cheung YP, Yu KN (2004) Analyses of airborne ${ }^{7} \mathrm{Be}$ concentrations in Hong Kong using back trajectories. Atmos Environ 38:7033-7040

Liu J, Song X, Sun X, Yuan G, Liu X, Wang S (2009) Isotopic composition of precipitation over arid Northwestern China and its implications for the water vapor origin. J Geogr Sci 19:164-174

Liu J, Song X, Yuan G, Sun X, Liu X, Wang S (2010a) Characteristics of $\delta^{18} \mathrm{O}$ in precipitation over Eastern Monsoon China and the water vapor sources. Chin Sci Bull 55: 200-211

Liu J, Fu G, Song X, Charles SP, Zhang Y, Han D, Wang S (2010b) Stable isotopic compositions in Australian precipitation. J Geophys Res 115:D23307 doi:10.1029/2010JD 014403 
Managave SR, Sheshshayee MS, Borgaonkar HP, Ramesh R (2010) Past break-monsoon conditions detectable by high resolution intra-annual $\delta^{18} \mathrm{O}$ analysis of teak rings. Geophys Res Lett 37:L05702 doi:10.1029/2009GL041172

McDermott F (2004) Palaeo-climate reconstruction from stable isotope variations in speleothems: a review. Quat Sci Rev 23:901-918

Merlivat L, Jouzel J (1979) Global climatic interpretation of the deuterium-oxygen 18 relationship for precipitation. J Geophys Res 84:5029-5033

Pfahl S, Wernli H (2008) Air parcel trajectory analysis of stable isotopes in water vapor in the eastern Mediterranean. J Geophys Res 113:D20104 doi:10.1029/2008JD009839

Rolph GD (2010) Real-time Environmental Applications and Display sYstem (READY). NOAA Air Resources Laboratory, Silver Spring, MD. Available at http://ready.arl. noaa.gov

Rozanski K, Araguás-Araguás L, Gonfiantini R (1993) Isotope patterns in modern global precipitation. In: Swart PK, Lohmann KC, McKenzie J, Savin S (eds) Climate

Editorial responsibility: Balaji Rajagopalan, Boulder, Colorado, USA change in continental isotopic records. Geophysical Monograph Series, Vol. 78. American Geophysical Union, Washington, DC, p 1-36

> Shan W, Yin Y, Lu H, Liang S (2009) A meteorological analysis of ozone episodes using HYSPLIT model and surface data. Atmos Res 93:767-776

> Strong M, Sharp ZD, Gutzler DZ (2007) Diagnosing moisture transport using D/H ratios of water vapor. Geophys Res Lett 34:L03404 doi:10.1029/2006GL028307

> Vreča P, Bronić IK, Horvatinčić N, Barešić J (2006) Isotopic characteristics of precipitation in Slovenia and Croatia: comparison of continental and maritime stations. J Hydrol (Amst) 330:457-469

Vuille M, Werner M, Bradley RS, Keimig F (2005) Stable isotopes in precipitation in the Asian monsoon region. J Geophys Res 110:D23108 doi:10.1029/2005JD006022

> Wei F, Xie Y, Mann ME (2008) Probabilistic trend of anomalous summer rainfall in Beijing: role of interdecadal variability. J Geophys Res 113:D20106 doi:10.1029/2008JD 010111

Submitted: August 16, 2010; Accepted: May 9, 2011 Proofs received from author(s): September 15, 2011 